\title{
Structural behavior of Pd40Cu30Ni10P20 bulk metallic glass below and above the glass transition
}

Mattern, N.; Hermann, H.; Roth, S.; Sakowski, J.; Macht, M.P.; Jovari, P.; Jiang, Jianzhong

Published in:

Applied Physics Letters

Link to article, DOI:

$10.1063 / 1.1567457$

Publication date:

2003

Document Version

Publisher's PDF, also known as Version of record

Link back to DTU Orbit

Citation (APA):

Mattern, N., Hermann, H., Roth, S., Sakowski, J., Macht, M. P., Jovari, P., \& Jiang, J. (2003). Structural behavior of Pd40Cu30Ni10P20 bulk metallic glass below and above the glass transition. Applied Physics Letters, 82(16), 2589-2591. https://doi.org/10.1063/1.1567457

\section{General rights}

Copyright and moral rights for the publications made accessible in the public portal are retained by the authors and/or other copyright owners and it is a condition of accessing publications that users recognise and abide by the legal requirements associated with these rights.

- Users may download and print one copy of any publication from the public portal for the purpose of private study or research.

- You may not further distribute the material or use it for any profit-making activity or commercial gain

- You may freely distribute the URL identifying the publication in the public portal 


\title{
Structural behavior of $\mathrm{Pd}_{40} \mathrm{Cu}_{30} \mathrm{Ni}_{10} \mathrm{P}_{20}$ bulk metallic glass below and above the glass transition
}

\author{
Norbert Mattern, ${ }^{\text {a) }}$ Helmut Hermann, and Stefan Roth \\ Leibniz-Institute for Solid State and Materials Research Dresden, P.O. Box 270016, \\ D-01171 Dresden, Germany \\ Jan Sakowski \\ Department of Physics, University Rostock D-18501 Rostock, Germany \\ Michael-Peter Macht \\ Hahn-Meitner Institute Berlin D-14109 Berlin, Germany \\ Pal Jovari \\ HASYLAB at DESY, Notkestr 85, D-22603 Hamburg, Germany \\ Jianzhong Jiang \\ Department of Physics, Technical University of Denmark, DK-2800 Lyngby, Denmark
}

(Received 20 December 2002; accepted 17 February 2003)

\begin{abstract}
The thermal behavior of the structure of $\mathrm{Pd}_{40} \mathrm{Cu}_{30} \mathrm{Ni}_{10} \mathrm{P}_{20}$ bulk metallic glass has been investigated in situ through the glass transition by means of high-temperature $\mathrm{X}$-ray synchrotron diffraction. The dependence of the x-ray structure factor $S(q)$ of the $\mathrm{Pd}_{40} \mathrm{Cu}_{30} \mathrm{Ni}_{10} \mathrm{P}_{20}$ glass on temperature follows the Debye theory up to the glass transition with a Debye temperature $\theta=296 \mathrm{~K}$. Above the glass transition temperature $T_{g}$, the temperature dependence of $S(q)$ is altered, pointing to a continuous development of structural changes in the liquid with temperature. The atomic pair correlation functions $g(r)$ indicate changes in short-range-order parameters of the first and the second neighborhood with temperature. The temperature dependence of structural parameters is different in glass and in supercooled liquid, with a continuous behavior through the glass transition. The nearest-neighbor distance decreases with temperature, changing the slope at $T_{g}$. The interatomic distances of higher coordination shells expand analogously to the macroscopic linear thermal expansion. (C) 2003 American Institute of Physics. [DOI: 10.1063/1.1567457]
\end{abstract}

Bulk metallic glasses are characterized by a high glassforming ability and the existence of a wide supercooled liquid region. ${ }^{1,2}$ The glass transition in this class of materials is an interesting physical phenomenon in general, but is also important for hot deformation of the material while preserving the amorphous structure. ${ }^{3}$ The atomic processes by which liquids become amorphous upon cooling or amorphous alloys transform into supercooled liquids upon heating have not been completely understood until now. The transition of the glass into the supercooled liquid state upon constant-rate heating gives an endothermic event in a differential scanning calorimetry (DSC) scan at the calorimetric glass transition temperature $T_{g}$, which is related to changes in thermodynamic properties (e.g., the enthalpy) and in the thermal expansion coefficient. ${ }^{4}$ On the other hand, the temperature dependence of relaxation times and diffusivity in bulk metallic glasses are discussed within the framework of the mode coupling theory with a critical temperature $T_{c}$ well above the calorimetric glass transition temperature. ${ }^{5,6}$ A direct observation of the structural behavior at the calorimetric glass transition temperature has been rather limited so $\mathrm{far}^{7,8}$ The aim of this work is to analyze the temperature dependence of the structure of $\mathrm{Pd}_{40} \mathrm{Cu}_{30} \mathrm{Ni}_{10} \mathrm{P}_{20}$ bulk glass in the glassy, the supercooled liquid, and the liquid state.

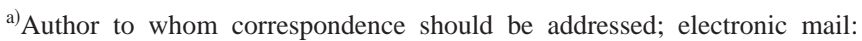
n.mattern@ifw-dresden.de
}

Samples of $\mathrm{Pd}_{40} \mathrm{Cu}_{30} \mathrm{Ni}_{10} \mathrm{P}_{20}$ bulk glasses were prepared in the form of rods with a $5-\mathrm{mm}$ diameter and a $50-\mathrm{mm}$ length by copper mold casting of the pre-alloy from the pure elements and refined by fluxing in $\mathrm{B}_{2}$. To remove the influence of structural relaxation, the samples were pre-annealed at $543 \mathrm{~K}$ for seven days. Disks of 1-mm height were cut from the rods for DSC and x-ray diffraction (XRD) experiments. Cylinders of $15 \mathrm{~mm}$ in length were used for the measurements of the thermal expansion. The DSC experiments were performed employing a Netzsch DSC 404 calorimeter (heating rate $10 \mathrm{~K} / \mathrm{min}$ ). The calorimetric glass transition temperature $T_{g}=569 \mathrm{~K}$ and the crystallization temperature $T_{x}$ $=663 \mathrm{~K}$ for the alloy agree well with values from literature (both characteristic temperatures are here defined as the onset temperatures of the respective endothermic and exothermic DSC heat flow events). The supercooled liquid region spreads over about $95 \mathrm{~K}$ for this alloy. The linear thermal expansion coefficients $\alpha$ were determined by a Netzsch DIL $402 \mathrm{C}$ dilatometer in the glassy state between 300 and $650 \mathrm{~K}$ at a heating rate of $5 \mathrm{~K} / \mathrm{min}$ to $\alpha=1.2 \times 10^{-5} / \mathrm{K}$, and in the liquid and undercooled liquid states from 973 to $820 \mathrm{~K}$ at a cooling rate of $-5 \mathrm{~K} / \mathrm{min}$ to $\alpha=\gamma / 3=3.1 \times 10^{-5} / \mathrm{K}$. In situ XRD measurements at elevated temperatures were conducted at the high-energy beamline BW5 (wavelength $\lambda$ $=0.01076 \mathrm{~nm}$ ) at the storage ring DORIS (HASYLAB, Hamburg). The experimental setup consisting of a hightemperature chamber and an image plate detector enables the 


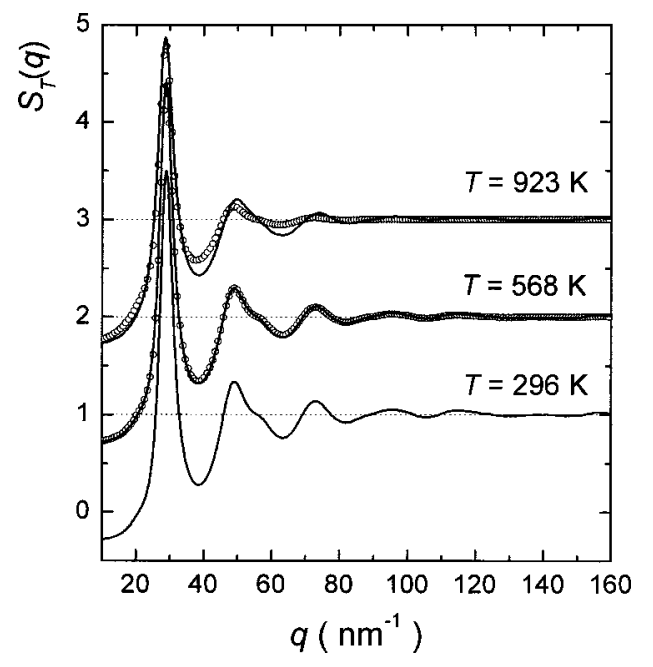

FIG. 1. Structure factor $S_{T}(q)$ of $\mathrm{Pd}_{40} \mathrm{Cu}_{30} \mathrm{Ni}_{10} \mathrm{P}_{20}$ at different temperatures (solid line: experimental data; circles: calculated using the Debye theory).

recording of a diffraction pattern in transmission within $30 \mathrm{~s}$ up to a scattering vector $q=200 \mathrm{~nm}^{-1}$. ${ }^{9}$ The sample was held for $140 \mathrm{~s}$ at the corresponding temperature $(30 \mathrm{~s}$ for exposure and additional $110 \mathrm{~s}$ for data readout time), and then heated up to the next temperature within $10 \mathrm{~s}$. Immediately thereafter, the measurement was started again. The mass density at ambient temperature was determined by the buoyancy method by weighing samples in air and in dodecan $\left(\mathrm{C}_{12} \mathrm{H}_{26}\right)$.

Figure 1 shows representative examples of the structure factor $S_{T}(q)$ of $\mathrm{Pd}_{40} \mathrm{Cu}_{30} \mathrm{Ni}_{10} \mathrm{P}_{20}$ measured in situ at elevated temperatures. The amorphous structure of the supercooled liquid is preserved up to $656 \mathrm{~K}$, which is $87 \mathrm{~K}$ above $T_{g}$. The beginning crystallization was observed at $T=673 \mathrm{~K}$ (not shown here), in agreement with the DSC data. Between $673 \mathrm{~K} \leqslant T \leqslant 823 \mathrm{~K}$, we observe crystalline reflections. At the next temperature investigated $(T=873 \mathrm{~K})$, the alloy is melted as expected from the liquidus temperature $\left(T_{1}\right.$ $=864 \mathrm{~K})$, determined by DSC. The diffuse character of the structure factor for $T \geqslant 873 \mathrm{~K}$ indicates the liquid state of the alloy, as shown for $T=923 \mathrm{~K}$ in Fig. 1. The diffraction curves of the amorphous state of the sample exhibit only small changes with increasing temperature. Figure 2 shows the temperature dependence of the position $q_{1}$ and the height $S\left(q_{1}\right)$ of the first maximum of structure factor. A continuous shift of $q_{1}$ with temperature to lower $q$-values is measured. No change in slope of $q_{1}$ at the glass transition temperature is observed. The height of the first maximum $S\left(q_{1}\right)$ decreases with increasing temperature for glass up to $T_{g}$ (Fig. $2)$. At the glass transition, the slope of $S\left(q_{1}\right)$ versus temperature is altered. As long as no crystallization sets in, the change in the temperature dependence of the structure factor at $T_{g}$ is reversible. The data shown in Fig. 2 were obtained for thermal cycling by heating up to $684 \mathrm{~K}(\triangle)$, cooling down to $373 \mathrm{~K}(\nabla)$, and subsequent reheating from 373 to $648 \mathrm{~K}(\Delta)$. The values of $S\left(q_{1}\right)$ for the cooling route below $625 \mathrm{~K}$ are $0.3 \%$ smaller compared to those of the first heating, but they are identical (deviation $<0.1 \%$ ) to the second reheating data. The small difference between the first and second heating may be related to different relaxation states, but this is also within the estimated error limit of about $1 \%$ but this is also within the estimated error limit of about $1 \%$ above $T_{g}$.

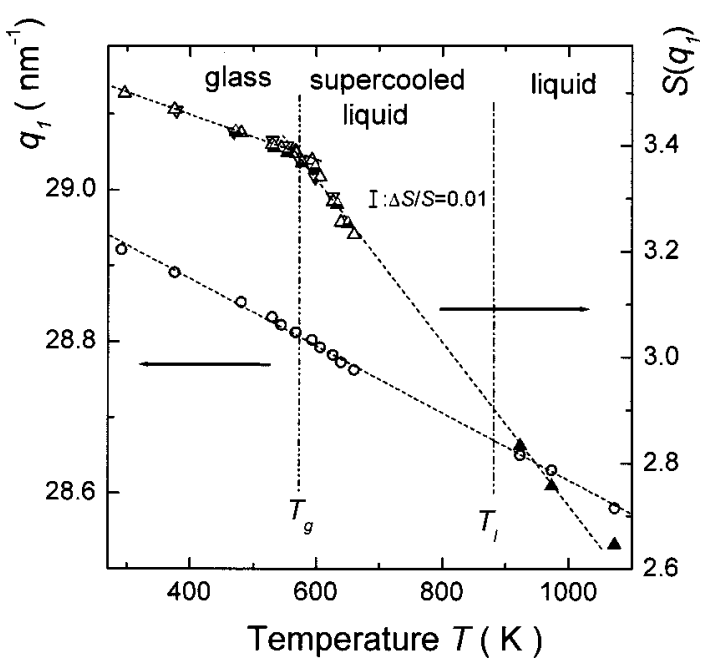

FIG. 2. Position $q_{1}$ and height $S\left(q_{1}\right)$ of the first maximum of the structure factor $S_{T}(q)$ vs temperature.

for the determination of $S\left(q_{1}\right)$. Experiments with enhanced accuracy are planned to study the influence of structural relaxation. The beginning crystallization is detected sensitively by an increase of $S\left(q_{1}\right)$ (not shown here). Extrapolating the temperature dependence of $S\left(q_{1}\right)$ from the supercooled liquid state to higher temperatures, one obtains approximately the experimental values for the molten $\mathrm{Pd}_{40} \mathrm{Cu}_{30} \mathrm{Ni}_{10} \mathrm{P}_{20}$ alloy $(\mathbf{\Delta})$. The temperature dependence of the $\mathrm{x}$-ray intensities can be described within the framework of the Debye theory. ${ }^{10}$ The structure factor at a temperature $T_{2}$ can be calculated from that at any other temperature $T_{1}$ by the relation

$$
\begin{aligned}
& \frac{S_{T_{2}}(q)-1}{S_{T_{1}}(q)-1}=\exp \left\{-2\left[W_{T_{2}}(q)-W_{T_{1}}(q)\right]\right\}, \\
& W_{T}=\frac{3 \hbar^{2} q^{2}}{2 m_{a} k_{\mathrm{B}} \Theta}\left(\frac{T}{\Theta}\right)^{2} \int_{0}^{\Theta / T}\left(\frac{1}{2}+\frac{1}{e^{z}-1}\right) z d z,
\end{aligned}
$$

where $\exp \left(-2 W_{T}\right)$ denotes the Debye-Waller factor, $\hbar$ is the Planck's constant, $k_{\mathrm{B}}$ is the Boltzmann's constant, $m_{a}$ is the mean atomic mass, and $\theta$ is the Debye temperature. The latter value can be calculated by a least squares fit of Eq. (1) to the data for the temperature dependence of the height of the first maximum of $S\left(q_{1}\right)$. One obtains $\theta=(296 \pm 10) \mathrm{K}$ for the $\mathrm{Pd}_{40} \mathrm{Cu}_{30} \mathrm{Ni}_{10} \mathrm{P}_{20}$ glass. Using Eq. (1) and choosing $T_{1}=296 \mathrm{~K}$ and $T_{2}=568 \mathrm{~K}$, the theoretical interference function for $T_{2}$ was calculated from the experimental curve measured at room temperature $T_{1}$. The calculated structure factor (circles) and the experimental curve (solid line) for $568 \mathrm{~K}$ agree well, as is shown in Fig. 1. This confirms the conclusion that only effects of atomic thermal vibrations, but no structural changes, appear within the temperature range from 293 to $568 \mathrm{~K}$. The temperature dependence of $S\left(q_{1}\right)$ in the supercooled liquid and liquid state $(573-1073 \mathrm{~K})$ gives a fictive Debye temperature of $\theta=(140 \pm 10) \mathrm{K}$. Applying Eq. (1) with $T_{1}=583 \mathrm{~K}$ and $T_{2}=923 \mathrm{~K}$, the theoretical $S(q)$ curve was calculated. The difference between the measured (solid line) and the calculated structure factor (circle) at 923 $\mathrm{K}$ in Fig. 1 points to the development of structural changes

to AlP license or copyright; see http://apl.aip.org/apl/copyright.jsp 


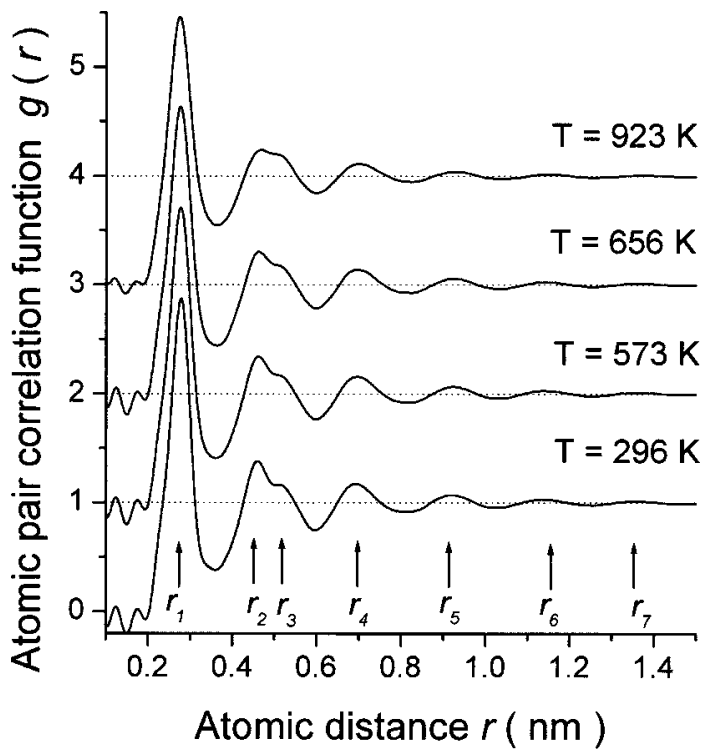

FIG. 3. Atomic pair correlation function $g(r)$ of $\mathrm{Pd}_{40} \mathrm{Cu}_{30} \mathrm{Ni}_{10} \mathrm{P}_{20}$ at different temperatures (maximum positions $r_{i}$ for $T=296 \mathrm{~K}: r_{1}=0.277, r_{2}$ $\left.=0.455, r_{3}=0.520, r_{4}=0.692, r_{5}=0.921, r_{6}=1.136, r_{7}=1.355 \mathrm{~nm}\right)$.

To analyze the structural behavior in real space, the atomic pair correlation functions $g(r)=\rho(r) / \rho_{0}$ were calculated by the Fourier transform of $S(q)$ between $0 \leqslant q$ $\leqslant 140 \mathrm{~nm}^{-1}$, according to: ${ }^{11}$

$$
4 \pi r \rho_{0}[g(r)-1]=\frac{2}{\pi} \int S(q) q \sin (q r) d q,
$$

where $\rho(r)$ is the radial atomic pair density distribution function and $\rho_{0}$ is the mean atomic density $\left[\rho_{0}=76 \mathrm{~nm}^{-3}\right.$ follows from the measured mass density $\sigma=(9.27$ $\left.\pm 0.01) \mathrm{g} \mathrm{cm}^{-3}\right]$. Figure 3 shows some of the calculated $g(r)$ curves. At room temperature, $S(q)$ and $g(r)$ look very similar to those of bulk amorphous $\mathrm{Pd}-\mathrm{Ni}-\mathrm{P}$ alloys, ${ }^{12}$ and also like many other transition-metal-metalloid glasses. The position of the first maximum in $g(r)$ of $\mathrm{Pd}_{40} \mathrm{Cu}_{30} \mathrm{Ni}_{10} \mathrm{P}_{20}$, $r_{1}=0.277 \mathrm{~nm}$, corresponds to the atomic diameter of palladium. The measured structure factor $S(q)$ and the estimated $g(r)$ curves represent in the four-component alloy the weighted sum of the 10 partial functions. ${ }^{11}$ The peaks of the pair correlation functions of $\mathrm{Pd}_{40} \mathrm{Cu}_{30} \mathrm{Ni}_{10} \mathrm{P}_{20}$ at elevated temperature become broader with increasing temperature. The nearest-neighbor number $N_{1}$, which is obtained by integration from 0.20 to $0.35 \mathrm{~nm}$ over the first maximum in $g(r)$, is constant within the error limits. The value of $N_{1}$ $=14.2$ is calculated for the glass at room temperature, and is 13.8 for the liquid at $T=973 \mathrm{~K}$. The split second maximum in $g(r)$ is also present in the melt with a reduced height of the first component.

The broadening of the first maximum is asymmetric with increasing atomic pair fractions at the larger distance site. In the supercooled liquid state, additional changes occur in $g(r)$ with temperature. The asymmetry becomes much more extended, and the height of first component of the second maximum at $r_{2}$ decreases more distinctively.

Figure 4 shows the relative thermal shift of some of the positions $r_{i}$ of maxima in $g(r)$ representing coordination shells. The first maximum corresponding to a weighted

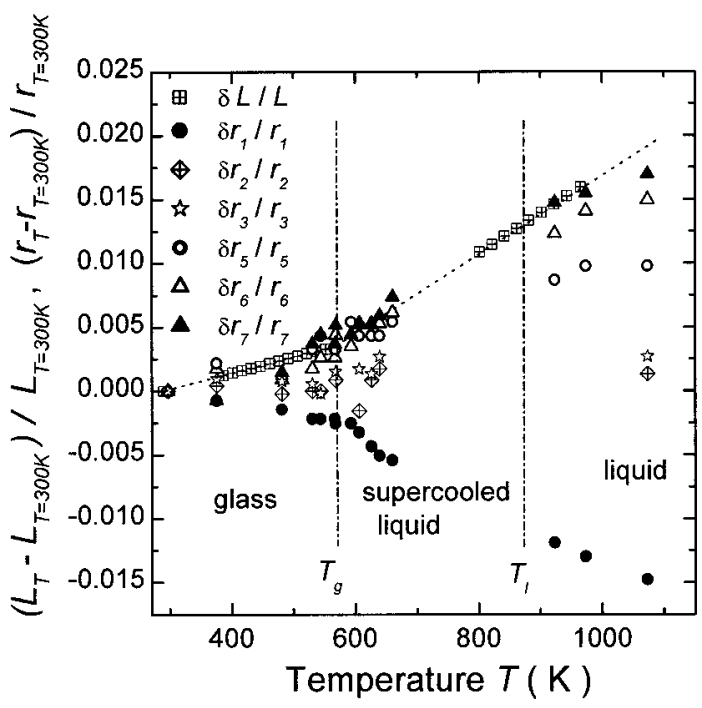

FIG. 4. Linear thermal expansion and the relative thermal shift of positions $r_{i}$ of maxima in $g(r)(i=1,2,3,5,6,7)$ of glassy and liquid $\mathrm{Pd}_{40} \mathrm{Cu}_{30} \mathrm{Ni}_{10} \mathrm{P}_{20}$ vs temperature.

nearest-neighbor distance decreases with increasing temperature. The slope of $r_{1}=r_{1}(T)$ changes at the glass transition. The distances of the second split maximum at $r_{2}$ and $r_{3}$ stay nearly constant in the whole temperature range. The distances of the higher coordination shells $r_{4}-r_{7}$ increase with a thermal expansion coefficient comparable to the macroscopic dilatometer measurements. The behavior of the structural parameters of the first and second neighborhood point to structural changes in the atomic arrangement of glassy and liquid $\mathrm{Pd}_{40} \mathrm{Cu}_{30} \mathrm{Ni}_{10} \mathrm{P}_{20}$ with temperature. Temperature dependence of chemically defined short-range order could lead to the shift of the individuals' partial contributions underlying the first maximum in $g(r)$. On the other hand, a constant value or even a small decrease of the first neighbor distance with temperature was also observed for pure metallic melts. ${ }^{13}$

In summary, the temperature dependence of structural parameters is different in glass and in supercooled liquid. Further work is necessary to clarify the origin of the variation in the short-range order with temperature.

${ }^{1}$ T. Zang, A. Inoue, and T. Masumoto, Mater. Trans., JIM 32, 1005 (1991).

${ }^{2}$ A. Peker and W. L. Johnson, Appl. Phys. Lett. 63, 2342 (1993).

${ }^{3}$ A. Inoue and A. Takeuchi, Mater. Trans., JIM 43, 1892 (2002).

${ }^{4}$ I.-R. Lu, G. P. Görler, H.-J. Fecht, and R. Willnecker, J. Non-Cryst. Solids 274, 294 (2000)

${ }^{5}$ A. Meyer, R. Busch, and H. Schober, Phys. Rev. Lett. 83, 5027 (1999).

${ }^{6}$ A. Meyer, J. Wuttke, W. Petry, A. Peker, R. Bormann, G. Coddens, L. Kranich, O. G. Randl, and H. Schober, Phys. Rev. B 53, 1210 (1996).

${ }^{7}$ H. Schumacher, U. Herr, D. Oelschlaeger, A. Traverse, and K. Samwer, J. Appl. Phys. 82, 155 (1997).

${ }^{8}$ N. Mattern, J. Eckert, U. Kuehn, H. Hermann, J. Sakowski, G. Herms, and J. Neuefeind, Appl. Phys. Lett. 80, 4525 (2002).

${ }^{9}$ J. Sakowski and G. Herms, in: Hasylab Annual Report, Part 1, 2000, p. 985.

${ }^{10}$ S. Sinha, P. L. Srivastava, and R. N. Singh, J. Phys.: Condens. Matter 1, 1695 (1989)

${ }^{11}$ C. N. J. Wagner, in Liquid Metals, Chemistry and Physics, edited by S. Z. Beer (Marcel Dekker, New York, 1972), p. 257.

${ }^{12}$ T. Egami, W. Dmowski, Y. He, and R. Schwarz, Metall. Mater. Trans. A 29, 1805 (1998).

${ }^{13}$ T. Schenk, D. Holland-Moritz, V. Simonet, R. Bellissent, and D. M. Herlach, Phys. Rev. Lett. 89, 075507 (2002). 